\title{
Diet-induced macrophage inhibitory cytokine 1 promotes prostate cancer progression
}

\author{
Mingguo Huang ${ }^{1,2,4}$, Shintaro Narita, ${ }^{1,4}$, Takamitsu Inoue ${ }^{1}$, Norihiko Tsuchiya, ${ }^{1,4}$, \\ Shigeru Satoh', Hiroshi Nanjo ${ }^{3}$, Takehiko Sasaki ${ }^{2,4}$ and Tomonori Habuchi ${ }^{1,4}$ \\ ${ }^{1}$ Department of Urology ${ }^{2}$ Research Center for Biosignal ${ }^{3}$ Department of Clinical Pathology, Akita University \\ Graduate School of Medicine, 1-1-1 Hondo, Akita 010-8543, Japan \\ ${ }^{4}$ CREST, Japan Science and Technology Agency (JST), Tokyo 102-0076, Japan
}

Correspondence should be addressed

to $M$ Huang

Email

huangmg@gipc.akita-u.ac.jp

\begin{abstract}
Recent studies have indicated that a high-fat diet (HFD) plays an important role in prostate cancer (PCa) progression. Palmitic acid (PA) is one of the most abundant saturated free fatty acids (FAs) and is associated with carcinogenesis. In this study, we investigated the mechanism underlying the association of dietary fat, including PA, with PCa progression. In four PCa cell lines, in vitro PA administration stimulated the expression of macrophage inhibitory cytokine 1 (MIC1), which is a divergent member of the transforming growth factor- $\beta$ family. In vivo, LNCaP xenograft tumor growth, serum MIC1 levels, and FA levels in xenograft tumors were significantly higher in mice receiving an HFD containing high amounts of PA than in those receiving a low-fat diet (LFD). In addition, tumor cells with high MIC1 expression invaded to venules and lymph vessels in the LNCaP xenograft. In vitro studies showed that proliferation and invasive capacity were significantly higher in PCa cells cultured with serum from HFD-fed mice than in those cultured with the serum from LFD-fed mice. This effect was attenuated by the addition of neutralizing antibodies against MIC1, but not by isotype control antibodies. Clinically, serum MIC1 levels were significantly higher in PCa patients than in healthy controls, and higher levels were associated with higher pathological grade and obesity. In conclusion, our results indicate that an HFD containing PA may promote growth and invasiveness of PCa cells through the upregulation of MIC1 expression.
\end{abstract}

\section{Key Words}

- prostate cancer

- high-fat diet

- palmitic acid

- macrophage inhibitory cytokine 1

\section{Introduction}

Prostate cancer (PCa) is the second leading cause of cancerrelated death in the USA (Hsing \& Devesa 2001), and epidemiological studies suggest that obesity and/or a highfat diet (HFD) can increase the incidence of PCa (Blair \& Fraumeni 1978, Andersson et al. 1997). The incidence of PCa is increasing rapidly in Japan, presumably because of increasingly westernized lifestyles, although it is still much lower than that in western nations (Tominaga 1985, Namiki et al. 2010). Furthermore, Japanese migrants in the USA have a markedly higher risk for PCa, suggesting that the development of PCa may be influenced by environmental factors, including diet (Shimizu et al. 1991). An HFD is believed to affect gene expression, cellular activity, and other important changes in circulating biological factors related to prostate carcinogenesis and progression (Narita et al. 2008, Huang et al. 2011, 2012). Recent large population-based studies have indicated that saturated fatty acids (SFAs), especially palmitic acid (PA), are

Published by Bioscientifica Ltd. 
significantly associated with higher incidence of PCa (Giovannucci et al. 1993, Kurahashi et al. 2008). In addition, high SFA consumption has been associated with biochemical recurrence as defined by increasing prostatespecific antigen (PSA) levels in patients treated with prostatectomy for PCa (Strom et al. 2008).

PA, one of the most abundant SFAs, is a major source of energy and is an important component of the lipids that comprise the cellular membrane. PA can be obtained from dietary fat or synthesized de novo by FA synthase (Flavin et al. 2011). It has also been reported that PA activates inflammatory pathways and induces the production of many cancer-related cytokines, such as interleukin 1 (IL1), IL6, and tumor necrosis factor- $\alpha$ (TNF- $\alpha$ ) in both humans and in mice (Haversen et al. 2009, Wen et al. 2011). In addition, a previous study suggested that PA was associated with the progression of breast cancer cells through the increased expression of macrophage inhibitory cytokine 1 (MIC1; Kim et al. 2008a). However, there is little evidence for the mechanism by which an HFD and/or PA induce cancer progression, especially that of PCa.

MIC1 is a divergent member of the transforming growth factor- $\beta$ (TGFB) family and is also known as placental bone morphogenetic protein (PLAB), prostatederived factor, and growth/differentiation factor 15 (Bootcov et al. 1997, Paralkar et al. 1998). MIC1 was first identified in monocytes and is also expressed in lung, liver, pancreas, kidney, prostate glands, and adipose tissue (Hromas et al. 1997). MIC1 is synthesized by proteolytic cleavage of an N-terminal propeptide, generating a dimeric or monomeric bioactive molecule that is secreted into the extracellular medium (Bootcov et al. 1997, Bauskin et al. 2005). Serum MIC1 levels are elevated in many patients with metastatic cancer, including that of the breast, colon, pancreas, and prostate (Brown et al. 2003, 2006, Koopmann et al. 2004, Wollmann et al. 2005).

In this study, we first examined the effects of PA on PCa cells. Because MIC1 was found to be elevated by PA administration, we then analyzed the role of MIC1 in HFD-associated PCa progression using in vitro and in vivo models. In humans, we also assessed the relationship among cancer aggressiveness, obesity, and serum MIC1 levels.

\section{Subjects and methods}

\section{Cells, culture conditions, and reagents}

Human PCa LNCaP, PC3, and DU145 cells were purchased from the American Type Culture Collection (Manassas,
VA, USA). Nonmalignant prostate PNT1B cells (Degeorges et al. 1995) and PCa C42 cells (Wu et al. 1994) were kindly provided by Dr Leland W K Chung (Emery University). The cells were maintained in RPMI 1640 media (Invitrogen) containing 10\% fetal bovine serum (FBS) and 1\% penicillin-streptomycin. FA-free (2\%) BSA (fraction V; Sigma) was used as a vehicle for PA (Sigma) treatment. PA was dissolved in water with $2 \%(\mathrm{w} / \mathrm{v}) \mathrm{BSA}$ and filtered through a 0.22- $\mu \mathrm{m}$ filter (SLGV004SL; Millipore, Billerica, MA, USA) before use. For PA treatment, $1 \times 10^{6}$ cells in a $35-\mathrm{mm}$ dish were serum starved for $4 \mathrm{~h}$ and treated with 0.125 or $0.25 \mathrm{mmol} / 1 \mathrm{PA}$ in serum-free DMEM (Invitrogen) for $24 \mathrm{~h}$. Recombinant human MIC1 (rMIC1) was purchased from R\&D Systems (Minneapolis, MN, USA) and used at a concentration of $20 \mathrm{ng} / \mathrm{ml}$. A capture antibody specific for MIC1, MAB957 (R\&D Systems), and the isotype control antibody, MAB004 (R\&D Systems), was used at a concentration of $10 \mu \mathrm{g} / \mathrm{ml}$.

\section{Animal study}

The Institutional Review Board of the Akita University School of Medicine approved all animal experiments. Sixweek-old BALB/c-nu/nu mice $(n=24)$ were obtained from Japan SLC (Shizuoka, Japan) and fed an autoclaved CE-2 diet (Japan SLC). For obtaining xenografts, $1 \times 10^{6} \mathrm{LNCaP}$ cells were s.c. inoculated with $0.25 \mathrm{ml}$ of ice-cold $\mathrm{BD}$ Matrigel (BD Bioscience, Bedford, MA, USA) and $0.25 \mathrm{ml}$ RPMI medium. Four weeks after injection, mice with a palpable tumor were randomly assigned to two different dietary groups ( $n=12$ for each group): HFD and low-fat diet (LFD). The average tumor size was 91.2 \pm 13.9 and $84.9 \pm 12.1 \mathrm{~mm}^{3}$ for the HFD and LFD groups respectively. The energy composition of the HFD was $59.9 \%$ from fats, $21.4 \%$ from carbohydrates, and $18.6 \%$ from proteins, whereas that of the LFD included 9.5\% from fats, $67.7 \%$ from carbohydrates, and $22.8 \%$ from proteins. These diets were prepared by Test Diet (Purina Mills Test Diets, Richmond, IN, USA). The FA content in the diets was measured, and it was found that the HFD and LFD included $6.6 \%(\mathrm{w} / \mathrm{w})$ and $0.3 \%(\mathrm{w} / \mathrm{w})$ PA respectively (Japan Food Research Laboratories, Tokyo, Japan). Body weight and tumor volume were measured weekly throughout the experiment. Tumor volume was calculated using the following formula: length $(\mathrm{cm}) \times$ width $(\mathrm{cm}) \times$ height $(\mathrm{cm}) \times 0.5236$ (Narita et al. 2008). Mice were killed at week 14, and xenograft tumors were excised for histopathological examination and FA quantification. Mouse serum was separated, filtered, and stored at $-80^{\circ} \mathrm{C}$ until use.

Published by Bioscientifica Ltd. 


\section{siRNA constructs}

siRNA was purchased from Ambion (Carlsbad, CA, USA). The sequences of siRNAs used in this study are as follows: MIC1 siRNA; siMIC1-l, 5'-GGCAGAAUCUUCGUCCGCAtt-3'; siMIC1-2, 5'-CCCGAUUCCUGCCCAAACAtt-3'; siMIC1-3，5'-GAGUUGCACUCCGAAGACUtt-3'; and GL2 Luciferase siRNA (control; Qiagen), 5'-AACGTACGCGGAATACTTCGA-3'. Transfection of siRNAs was carried out using Lipofectamine 2000 (Invitrogen). Cells were treated with $50 \mathrm{nmol} / 1$ siRNA in reduced-serum DMEM. MIC1 knockdown was verified using quantitative RT-PCR (qRT-PCR) and western blotting.

\section{Quantitative RT-PCR}

Total RNA was extracted from cultured cells using TRIzol reagent (Invitrogen), and cDNA was synthesized using Superscript 2 reagent (Invitrogen), according to the manufacturer's instructions. PCR conditions were $90{ }^{\circ} \mathrm{C}$ for $30 \mathrm{~s}, 60^{\circ} \mathrm{C}$ for $30 \mathrm{~s}$, and $72^{\circ} \mathrm{C}$ for $45 \mathrm{~s}$. The following primers were used: $M I C 1$, forward $5^{\prime}$-CGCGCAACGGGGACCACT-3', reverse 5'-TGAGCACCATGGGATTGTAGC3'; TGF-fi, forward 5'-GACATCAACGGGTTCAC-3', reverse 5'-GAAGTTGGCATGGTAGC-3'; and $\beta$-actin, forward 5'-ATCTGGCACCACACCTTCTA-3', reverse 5'-CGTCATACTCCTGCTTGCTGATCCACATCTGC-3'. All experiments were performed in triplicate.

\section{Cell proliferation assay}

A total of $1 \times 10^{4}$ cells were seeded in a 96-well plates and cultured in DMEM containing 5\% FBS and 5\% mouse serum for $24 \mathrm{~h}$ with or without the MIC1-specific neutralizing antibody MAB957, the isotype control antibody MAB004, or rMIC1. Cell proliferation was assessed using a nonradioactive 3-(4,5-dimethylthiazol-2-yl)-2,5-diphenyltetrazolium bromide (MTT)-based cell proliferation assay kit (Roche), according to the manufacturer's instructions. Absorbance was measured at $570 \mathrm{~nm}$ using an ELISA reader (Bio-Rad). All experiments were performed in triplicate.

\section{Western blot analysis}

Proteins were isolated from the cultured cells and supernatants. Equal amounts of protein or culture medium were separated by SDS-PAGE and transferred to PVDF membranes (ATTO Instruments, Tokyo, Japan). The membranes were blocked for $1 \mathrm{~h}$ at room temperature using 1\% nonfat dry milk in PBS containing 0.1\% Tween
20 and incubated for $1 \mathrm{~h}$ at room temperature in antiMIC1, anti-ERK1/2, anti-phospho-ERK1/2 (p-ERK1/2, Thr202/Tyr204), or anti- $\beta$-actin (Cell Signaling Technology, Beverly, MA, USA) antibodies, diluted 1:1000 in blocking buffer. Membranes were washed and incubated with goat anti-rabbit IgG coupled to horseradish peroxidase (1:3000, Santa Cruz Biotechnologies). Proteins were visualized using an ECL system (Amersham Biosciences) and quantified by densitometry.

\section{Matrigel invasion assay}

The in vitro invasion assay was performed in triplicate using Growth Factor Reduced BD BioCoat Matrigel Invasion Chambers (BD Biosciences), according to the manufacturer's instructions. Briefly, $5 \times 10^{4}$ cells were seeded in the upper chamber with a medium containing 5\% FBS or 5\% mouse serum with or without $10 \mu \mathrm{g} / \mathrm{ml}$ MAB957 or MAB004, or $20 \mathrm{ng} / \mathrm{ml}$ rMIC1. Subsequently, 20\% FBS DMEM was placed in the lower chamber, followed by incubation for $24 \mathrm{~h}$. In siRNA experiments, cells had been previously treated with $50 \mathrm{nmol} / 1$ MIC1 siRNA for $24 \mathrm{~h}$. Subsequently, the noninvading cells were removed and the membranes were stained with a Diff-Quik cell-staining kit (Sysmex, Kobe, Japan) to count the invading cells.

\section{FFA quantification}

Quantification of FFA storage in xenograft tumors was performed in triplicate using a FFA quantification kit (Biovision, Mountain View, CA, USA), according to the manufacturer's instructions. Briefly, $10 \mathrm{mg}$ tumor tissue was extracted by homogenization with $200 \mu$ l chloroformTriton X-100 (1\% Triton X-100 in pure chloroform). The extract was centrifuged, the organic lower phase was collected, and samples were air dried at $50{ }^{\circ} \mathrm{C}$. The dried lipids were dissolved in $200 \mu \mathrm{l} \mathrm{FA}$ assay buffer and converted to acyl-CoA. The oxidized reaction and generated color were measured at $570 \mathrm{~nm}$, and the concentration was calculated using a PA standard curve.

\section{Histopathological analysis}

The sections of formalin-fixed paraffin-embedded xenograft tumors were stained with rabbit anti-human MIC1 polyclonal antibody (Cell Signaling) used at a 1:100 dilution. After overnight incubation, the tissue sections were incubated with HRP-labeled anti-rabbit antibody at a 1:5000 dilution. To assess the invasion of venules and lymph vessels, Elastica-Masson and D2-40

Published by Bioscientifica Ltd. 
(Nichirei Biosciences, Inc., Tokyo, Japan) staining were performed. The intensity of MIC1 staining intensity in venules and lymph vessels of the xenograft tumors was scored semi-quantitatively on a three-point scale as follows: 1, low; 2, moderate, and 3, high.

\section{Determination of serum MIC1 levels}

Human serum samples were obtained from $168 \mathrm{PCa}$ patients and 54 healthy controls (male kidney donors for transplantation). The mean age, BMI, and PSA levels of PCa patients were $67.9 \pm 5.5$ years, $24.1 \pm 2.2 \mathrm{~kg} / \mathrm{m}^{2}$, and $46.1 \pm 64.2 \mathrm{ng} / \mathrm{ml}$ respectively. The mean age, BMI, and serum creatinine levels of the healthy kidney donors were $60.9 \pm 10.9$ years, $22.9 \pm 2.4 \mathrm{~kg} / \mathrm{m}^{2}$, and $0.7 \pm 0.1 \mathrm{mg} / \mathrm{dl}$ respectively (Supplementary Table 1 , see section on supplementary data given at the end of this article). The Institutional Review Board of the Akita University School of Medicine approved all experiments, and samples were obtained after written informed consent was provided by all patients. From each patient, $4 \mathrm{ml}$ of blood was drawn and the serum was separated by centrifugation, and then aliquoted and stored at $-80^{\circ} \mathrm{C}$ until assay. The subjects were enrolled between 2006 and 2010, after being referred to the Department of Urology at Akita University. The serum samples from the patients were used as a pretreatment before anticancer therapy. Serum MIC1 levels were measured using a sandwich ELISA Kit (Oxford Biomedical Research, Inc., Oxford, MI, USA), according to the manufacturer's instructions. We also measured the concentration of human MIC1 both in the serum of the xenograft mice and in the conditioned medium of the PCa cells treated with PA using human-specific ELISA that does not cross-react with mouse MIC1.

\section{Statistical analysis}

Statistical analyses were performed using Microsoft Excel (Microsoft Corporation) and SPSS version 12 (IBM) Software. The statistical significance of the differences between two means in each experiment was evaluated using the unpaired Student's $t$-test. Differences among three or more groups were tested using one-way ANOVA for continuous variables or the Kruskal-Wallis test. The correlation coefficient was calculated to investigate the relationship between serum MIC1 levels and volume of xenograft tumors. A positive correlation was considered when an $r$ value of $>0.5$ was obtained. Differences were considered significant if the $P$ value was $<0.05$.

\section{Results}

\section{Upregulation of MIC1 by PA in PCa cells}

Taking into account the recent evidence suggesting that PA stimulates MIC1 expression in breast cancer cells (Kim et al. 2008a), we first examined whether PA stimulated MIC1 expression in PCa and benign prostate cells. MIC1 mRNA expression was increased in PCa LNCaP, PC3, and DU145 cells after treatment with $0.25 \mathrm{mmol} / 1 \mathrm{PA}$. Furthermore, expression was significantly higher in PCa cells treated with $0.25 \mathrm{mmol} / \mathrm{l} \mathrm{PA}$ for $24 \mathrm{~h}$ than in benign PNT1B cells (Fig. 1A). In contrast, $T G F B$ mRNA expression was not significantly changed in PCa cells after treatment with $0.25 \mathrm{mmol} / \mathrm{l}$ PA (Supplementary Fig. 1, see section on supplementary data given at the end of this article). We also examined MIC1 protein expression after PA treatment in LNCaP and C4-2 cells. MIC1 protein expression was increased after treatment with $0.25 \mathrm{mmol} / \mathrm{l} \mathrm{PA}$ in a time-dependent manner (Fig. 1B). Next, we assessed soluble MIC1 (sMIC1) expression in the conditioned medium of LNCaP and C42 cells with or without PA treatment. Dimeric sMIC1 (molecular weight, $\sim 28 \mathrm{kDa}$ ) expression was significantly higher in PCa cells treated with PA. However, there was no difference in protein expression for the two different concentrations of PA (0.25 and $0.125 \mathrm{mmol} / \mathrm{l}$; Fig. 1C). The MIC1 concentration in the conditioned medium from the above experiments was measured and found to be significantly higher in a medium containing cells treated with PA (Fig. 1D).

\section{Increased tumor growth, FA storage, and MIC1 expression in LNCaP xenograft tumors in HFD mice}

After 4 weeks, mice with palpable tumors were randomly assigned to two different diet groups (HFD and LFD, 12 mice in each group). There was no significant difference in body weight or caloric intake between the HFD and LFD groups (data not shown). At the end of the experiment (week 14), the mean tumor volume was significantly higher in the HFD group than in the LFD group (2569.9 \pm 151.1 and $2010.3 \pm 120.7 \mathrm{~mm}^{3}$, respectively, $P=0.025$; Fig. 2A), which was in accordance with the results of previous studies (Huang et al. 2012). The amount of FA storage in tumors was found to be significantly higher in the HFD group than in the LFD group $(172.2 \pm 43.9$ and $119.6 \pm 17.8 \mathrm{nmol} / \mathrm{mg}$, respectively, $P<0.001$; Fig. 2B). Furthermore, serum MIC1 levels were significantly higher in the HFD group than in the LFD group

Published by Bioscientifica Ltd. 


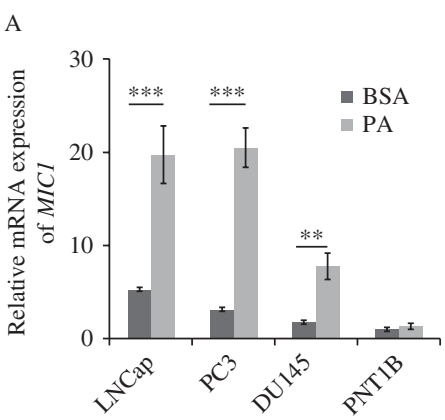

C

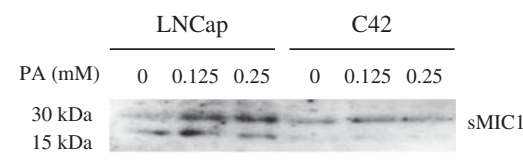

B

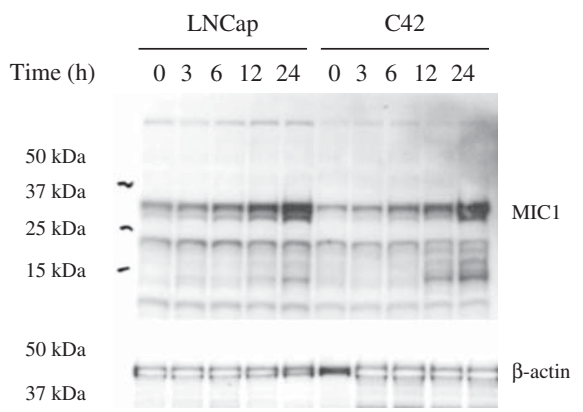

$\mathrm{D}$

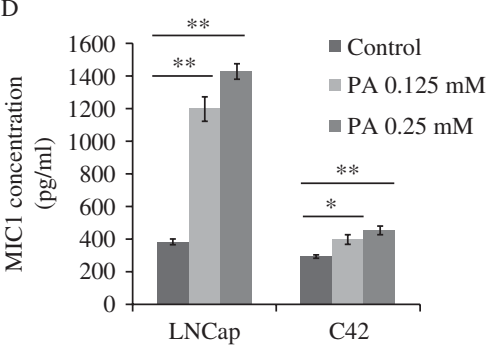

\section{Figure 1}

PA stimulates MIC1 expression in PCa cells. (A) PCa cell lines, LNCaP, PC3, and DU145 cells, and benign prostate PNT1B cells were treated with $0.25 \mathrm{mmol} / \mathrm{l}$ palmitic acid (PA) or $2 \%$ BSA for $24 \mathrm{~h}$. Cells were harvested, total RNA was extracted and quantitative RT-PCR was performed to detect MIC1. Mean \pm s.D., $* * P<0.01, * * * P<0.001$. (B) $\mathrm{LNCaP}$ and $\mathrm{C} 42$ cells were cultured with $0.25 \mathrm{mmol} / \mathrm{I} \mathrm{PA}$ or $2 \%$ BSA for the indicated time periods. Western blot analysis was performed with anti-human MIC1 and anti- $\beta$ actin antibodies. (C) LNCaP and C42 cells were cultured in serum-free

(24 $155.2 \pm 4281.6$ and $18343.8 \pm 7019.9 \mathrm{pg} / \mathrm{ml}$, respectively, $P=0.012$; Fig. 2C). There was a significant correlation between tumor volume and serum MIC1 levels (total, $r=0.642, P=0.022$; HFD group, $r=0.710, P=0.016$; and LFD group, $r=0.629, P=0.028$; Fig. 2D). We confirmed MIC1 protein expression in the xenograft tumors using immunohistochemistry. MIC1 was mainly expressed in the cytoplasm of the PCa cells in the xenograft tumors, but it was also detected in the tumor stroma. The intensity of MIC1 immunostaining was higher in the HFD group (Fig. 2E, left) than in the LFD group (Fig. 2E, right). These findings indicated that the HFD upregulated FA storage and MIC1 overexpression in the LNCaP xenograft tumors as well as accelerating tumor growth.

\section{Upregulation of MIC1 modulates PCa cell proliferation and ERK activation}

To address the direct effects of the HFD and MIC1 overexpression on PCa cell proliferation, we performed an MTT-based cell proliferation assay. The proliferation rate was significantly higher in $\mathrm{LNCaP}$ and $\mathrm{C} 42$ cells
DMEM with $2 \%$ BSA or 0.125 or $0.25 \mathrm{mmol} / \mathrm{l}$ PA for $24 \mathrm{~h}$. Proteins from equal volumes of culture medium were subjected to western blot analysis using anti-human MIC1 antibody. (D) The MIC1 concentration of the conditioned medium derived from (C) was measured using a human MIC1 ELISA Kit. Mean \pm s.D., ${ }^{*} P<0.05, * * P<0.01$. (D) LNCaP and C42 cells were cultured in serum-free DMEM with $2 \%$ BSA or 0.125 or $0.25 \mathrm{mmol} / \mathrm{l} \mathrm{PA}$ for $24 \mathrm{~h}$. Proteins from equal volumes of culture medium were subjected to western blot analysis using anti-human MIC1 antibody.

cultured in a medium containing 5\% HFD mouse serum than in those cultured in a medium containing 5\% FBS. These effects were attenuated in the presence of an MIC1specific capture antibody MAB957, but not in the presence of control antibody MAB004 (Fig. 3A and Supplementary Fig. 3, see section on supplementary data given at the end of this article). Furthermore, the cell proliferation rate observed in the medium containing 5\% FBS in the presence of MAB957 or MAB004 was similar to the rate in the medium without antibodies (Supplementary Fig. 3). The proliferation rate of $\mathrm{LNCaP}$ and $\mathrm{C} 42$ cells cultured in a medium containing 5\% HFD mouse serum was 1.2 and 1.3 times higher, respectively, than that of the cells cultured in a medium containing 5\% LFD mouse serum $(n=4$ per group, $P<0.05 ;$ Fig. $3 \mathrm{~A})$. The cell proliferation rate in both LNCaP and C42 cells increased after treatment with rMIC1 in a dose-dependent manner, and it was significantly higher than that after treatment with FBS alone $(P<0.05$; Fig. 3A). Because MIC1 activates the ERK signaling pathway in breast cancer (Kim et al. $2008 b$ ), we next examined ERK1/2 expression in the PCa cells treated with xenograft mouse serum or rMIC1.

Published by Bioscientifica Ltd. 
A

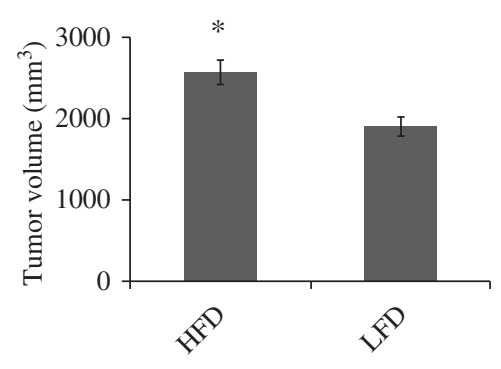

C

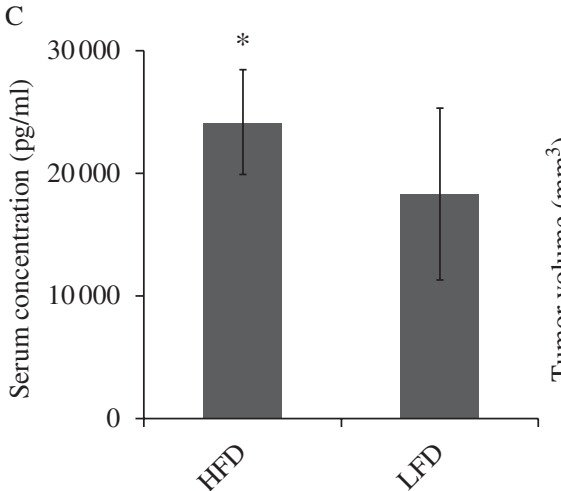

E

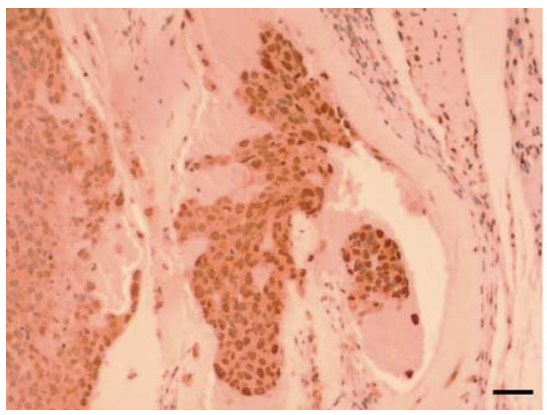

B

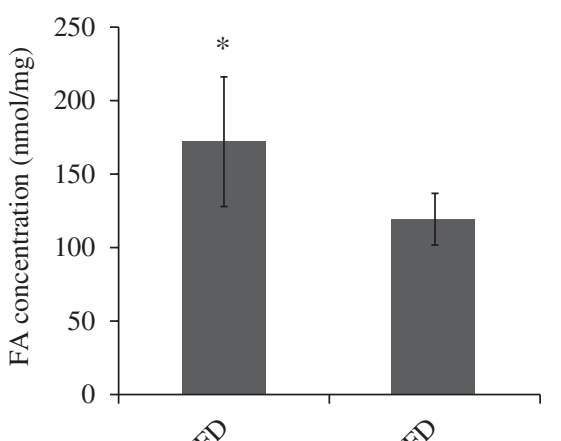

D
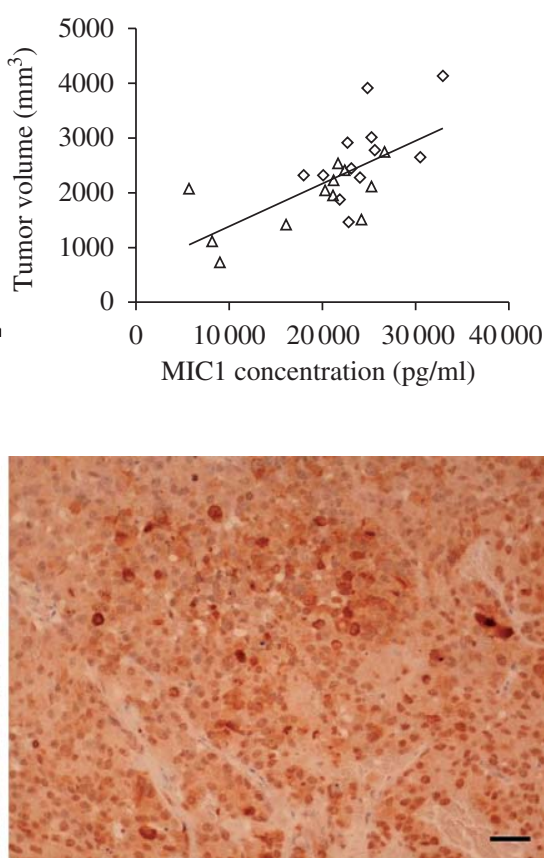

\section{Figure 2}

A high-fat diet (HFD) increases tumor growth, fatty acid (FA) storage, and MIC1 expression and secretion in LNCaP xenograft-recipient mice. Twentyfour mice with xenografted tumors were randomly assigned to two groups and fed an HFD or an LFD. (A) Tumor volume was measured at 14 weeks. Mean \pm s.D., ${ }^{*} P<0.05$. (B) FA storage in xenograft tumor tissue was measured using a free fatty acid quantification kit. Mean \pm s.D., $* P<0.05$. (C) Serum MIC1 levels in xenograft-recipient mice were measured using a human MIC1

pERK1/2 expression was significantly higher in the LNCaP cells cultured with 5\% HFD mouse serum, 5\% LFD mouse serum, or $20 \mathrm{ng} / \mathrm{ml}$ rMIC1 than in those cultured with 5\% FBS. The effects were significantly inhibited by MAB957 (Fig. 3B and Supplementary Fig. 5, see section on supplementary data given at the end of this article). These findings indicated that MIC1 is one of the important factors enhancing PCa cell proliferation in the presence of HFD mouse serum and that this proliferation involves ERK1/2 activation.
ELISA Kit. Mean \pm s.D., $* P<0.05$. (D) Serum MIC1 levels and tumor volumes from xenograft-recipient mice were plotted for each individual animal, and the correlation coefficient $(r)$ was calculated using SPSS version 12 Software (total, $r=0.642, P=0.022$; HFD group, open squares, $r=0.710, P=0.016$; LFD group, open triangles, $r=0.629, P=0.028$ ). (E) Xenograft tumor sections from mice fed the HFD (left) or the LFD (right) were examined using immunostaining for anti-human MIC1 antibody (bar, $100 \mu \mathrm{m})$.

\section{Upregulation of MIC1 modulates invasive capacity in PCa cells}

Next, we investigated the effects of diet-induced upregulation of MIC1 on PCa invasiveness using the Matrigel invasion assay. The invasive capacity was significantly higher in PC3 and DU145 cells cultured in a medium containing xenograft mouse serum than in those cultured in FBS media, and the effects were attenuated in the presence of MAB957, but not in the presence of control antibody MAB004 ( $n=4$ per group, ${ }^{*} P<0.05$; Fig. 4 A, B and

Published by Bioscientifica Ltd. 

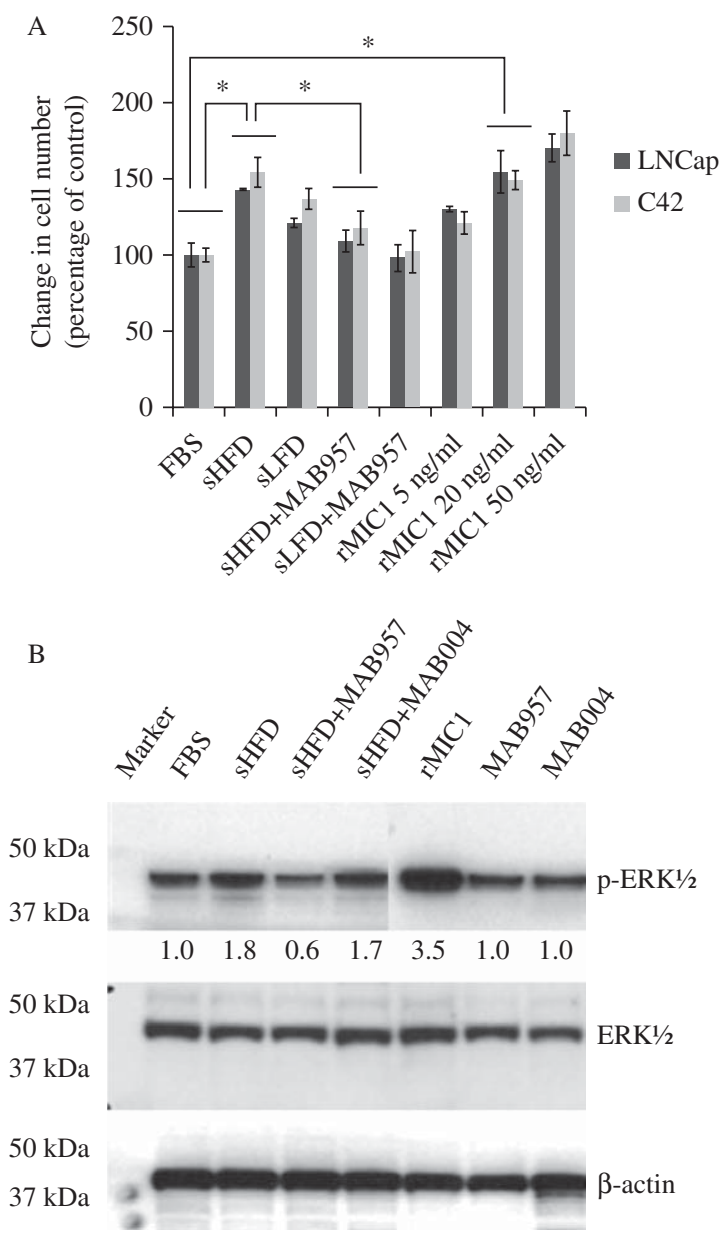

\section{Figure 3}

Administration of MIC1 stimulates cell proliferation and ERK1/2 activation in PCa cells. (A) LNCaP and C4-2 cells were cultured with DMEM containing $5 \% \mathrm{FBS}$ or $5 \%$ mouse serum in the presence or absence of the anti-MIC1 neutralizing antibody MAB957 or recombinant MIC1 at the indicated concentrations for $24 \mathrm{~h}$. MTT assay was performed and cell viability was compared with that of cells cultured with FBS. Mean \pm s.D., $* P<0.05$. (B) LNCaP cells were cultured with DMEM containing $5 \% \mathrm{FBS}$ or $5 \% \mathrm{HFD}$ mouse serum in the presence or absence of MAB957 or MAB004 or $20 \mathrm{ng} / \mathrm{ml}$ rMIC1 for $15 \mathrm{~min}$. In the same experiments, the DMEM containing $5 \%$ HFD mouse serum had been previously incubated with $10 \mu \mathrm{g} / \mathrm{ml}$ MAB97 or MAB004 at $4{ }^{\circ} \mathrm{C}$ overnight. Western blot analysis was performed using antiERK1/2, anti-phospho-ERK1/2 (p-ERK1/2), and anti- $\beta$ actin antibodies.

Supplementary Fig. 4, see section on supplementary data given at the end of this article). In addition, PCa cell invasiveness in the FBS medium in the presence of MAB957 or MAB004 was similar to that observed in the medium without antibodies (Supplementary Fig. 4). The invasive capacity of PC3 and DU145 cells was significantly higher after treatment with $20 \mathrm{ng} / \mathrm{ml} \mathrm{rMIC} 1$ than after treatment with $5 \% \mathrm{FBS}\left({ }^{*} P<0.01\right.$; Fig. $4 \mathrm{~A}$ and B). Furthermore, siRNAmediated knockdown of MIC1 decreased invasive capacity of both PC-3 and DU145 cells by 0.6 times $(P<0.05$;
Fig. 4A and B and Supplementary Fig. 2A and B, see section on supplementary data at the end of this article).

\section{Invading cancer cells exhibit high MIC1 expression in LNCaP xenograft tumors}

We next assessed MIC1 expression in tumor and peritumoral vessels of the LNCaP xenograft tumors using MIC1 immunohistochemistry and evaluated the relationship between MIC1 expression and invasive capacity in vivo. To delineate the specific location, Elastica-Masson staining and D2-40 immunostaining were performed to detect venules and lymph vessels respectively. Several sections of the LNCaP xenograft tumors showed clusters of tumor cells invading venules (Fig. 4C, left) and lymph vessels (Fig. 4C, right). MIC1 expression in vessels around the LNCaP xenograft tumors was higher in the HFD group than in the LFD group (venules, $2.7 \pm 0.4$ and $2.0 \pm 0, P=0.116$; lymph vessels, $2.5 \pm 0.5$ and $2.0 \pm 1.0, P=0.453$ respectively). Although not statistically significant, the LNCaP xenograft tumors exhibited greater invasion of peritumoral venules and lymph vessels in the HFD group than in the LFD group ( 33.3 and $16.7 \%, P=0.346 ; 50.0$ and $16.7 \%$, $P=0.083$ respectively; Fig. 4 C). These findings indicate that the HFD increased the capacity of tumor cells to invade peritumoral vessels by enhancing MIC1 expression in LNCaP cells in tumors originating from xenografts.

\section{Increased serum MIC1 levels in PCa patients correlate with disease aggressiveness and BMI}

To investigate the role of MIC1 expression in cancer aggressiveness and obesity in PCa patients, we measured serum MIC1 levels in 54 healthy controls and 168 patients with localized PCa treated with radical prostatectomy. Serum MIC1 levels were significantly higher in the PCa patients than in the controls $(1154.2 \pm 889.9$ and $784.0 \pm$ $299.6 \mathrm{pg} / \mathrm{ml}$, respectively, $P=0.002$; Fig. $5 \mathrm{~A}$ ). When the PCa patients were divided into three groups according to Gleason score (GS), serum MIC1 levels were significantly higher in patients with high-grade tumors than in patients with low-grade and moderate-grade tumors (ANOVA, $P=0.013$; high grade vs moderate, $P=0.008$; high grade vs low grade, $P=0.003$; high grade vs control, $P=0.001$; moderate vs low grade, $P=0.271$; moderate vs control, $P=0.017$; and low grade vs control, $P=0.036$; Fig. $5 B$ ). As shown in Supplementary Table 2, see section on supplementary data given at the end of this article, serum MIC1 levels in the PCa patients were significantly associated with clinical stage $(P<0.01)$, GS $(P<0.02)$, and serum PSA levels $(P<0.01)$.

Published by Bioscientifica Ltd 
A

PC3
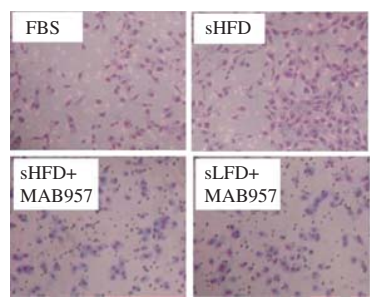

DU145
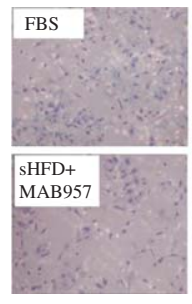

C
B
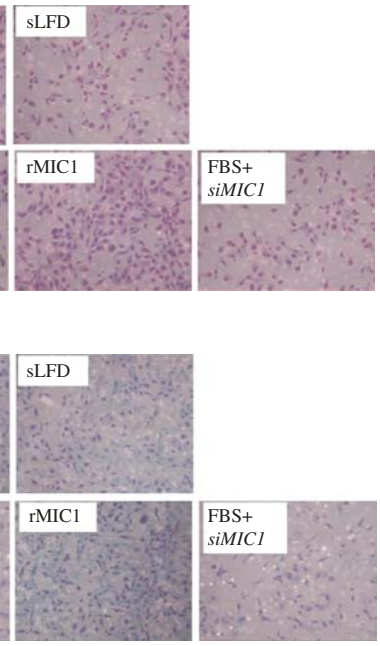
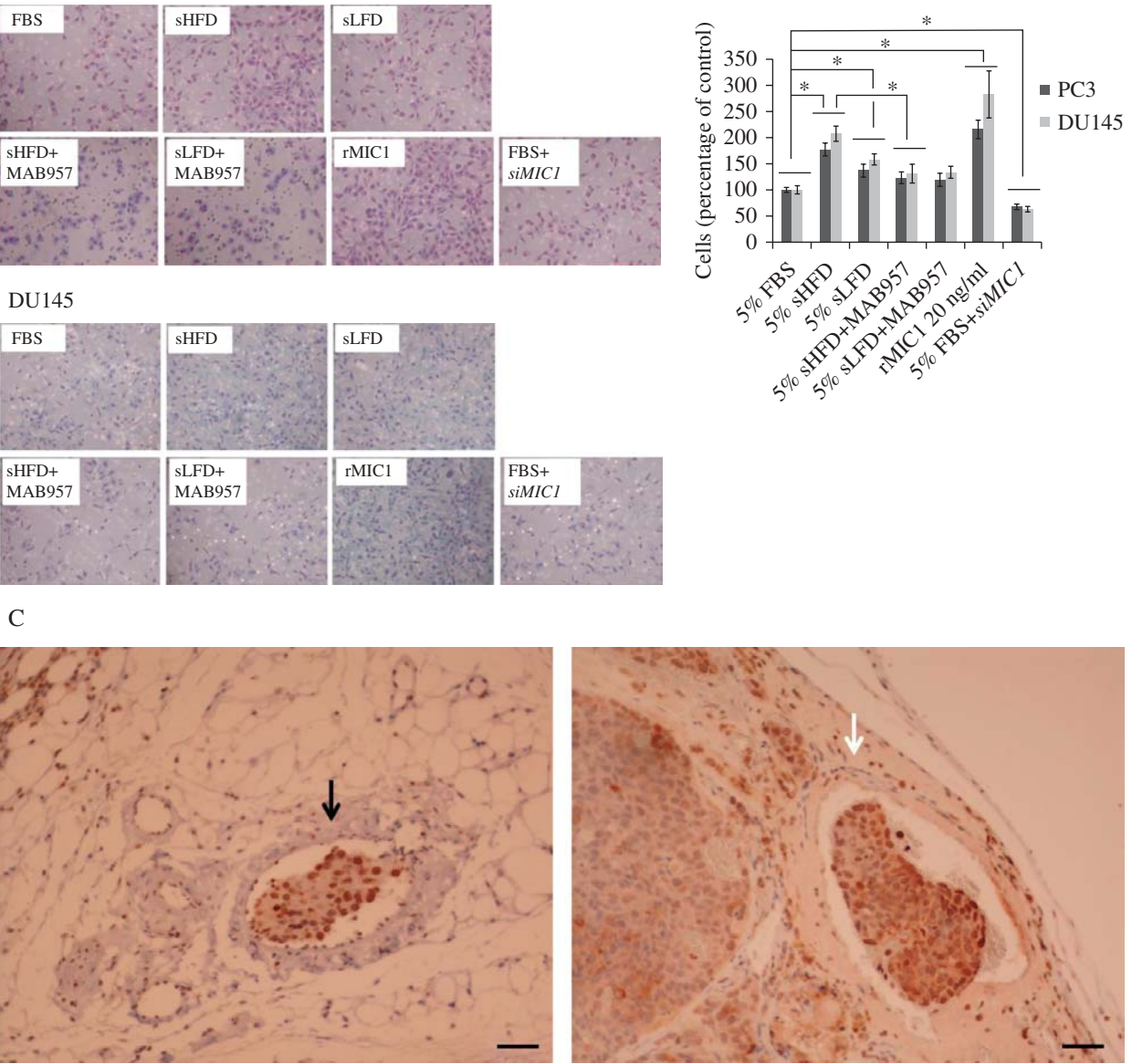

\begin{tabular}{|l|c|c|c|c|}
\hline & \multicolumn{2}{|c|}{ HFD group } & \multicolumn{2}{c|}{ LFD group } \\
\hline & $\begin{array}{c}\text { Incidence, } \\
n(\%)\end{array}$ & $\begin{array}{c}\text { Intensity, } \\
\text { mean } \pm \mathrm{SD}\end{array}$ & $\begin{array}{c}\text { Incidence, } \\
n(\%)\end{array}$ & $\begin{array}{c}\text { Intensity, } \\
\text { mean } \pm \text { SD }\end{array}$ \\
\hline Venules & $4 / 12(33.3 \%)$ & $2.7 \pm 0.4$ & $2 / 12(16.7 \%)$ & $2.0 \pm 0$ \\
\hline Lymph vessels & $6 / 12(50.0 \%)$ & $2.5 \pm 0.5$ & $2 / 12(16.7 \%)$ & $2.0 \pm 1.0$ \\
\hline
\end{tabular}

\section{Figure 4}

Increased MIC1 enhances the invasiveness of PCa cells. Representative images (A) and a histogram (B) showing the invasive capacity of PC3 and DU145 cells cultured for $24 \mathrm{~h}$ with DMEM containing $5 \%$ FBS in the presence or absence of $M I C 1$ siRNA and $5 \%$ xenograft mouse serum, in the presence or absence of the anti-MIC1 neutralizing antibody MAB957 or $20 \mathrm{ng} / \mathrm{ml} \mathrm{rMIC1}$. All invaded cells were counted and their numbers were

When the PCa patients were divided into two groups according to median BMI, mean serum MIC1 levels were higher in patients with a higher BMI than in those with a lower BMI $(1411.3 \pm 1353.3$ and $1137.5 \pm 1076.4 \mathrm{pg} / \mathrm{ml}$, respectively, $P=0.087$; Fig. $5 \mathrm{C})$. These findings indicated that increased serum MIC1 levels may be associated with cancer aggressiveness and obesity in PCa patients. compared with those of cells cultured with FBS. Mean \pm S.D., $* P<0.05$. (C) Immunohistochemistry with anti-human MIC1 antibody was performed for xenograft tumor sections, and the number of cancer cells invading venules (black arrow, left) and lymph vessels (white arrow, right) was determined using a microscope. Incidence and intensity of invasion were evaluated (below).

\section{Discussion}

PA is one of most abundant SFA, and epidemiological studies have suggested that higher PA intake is a risk factor for the incidence and progression of $\mathrm{PCa}$ (Giovannucci et al. 1993, Kurahashi et al. 2008). Unlike unsaturated FA, SFA activates inflammasomes and induces many inflammatory cytokines in several target tissues

Published by Bioscientifica Ltd 

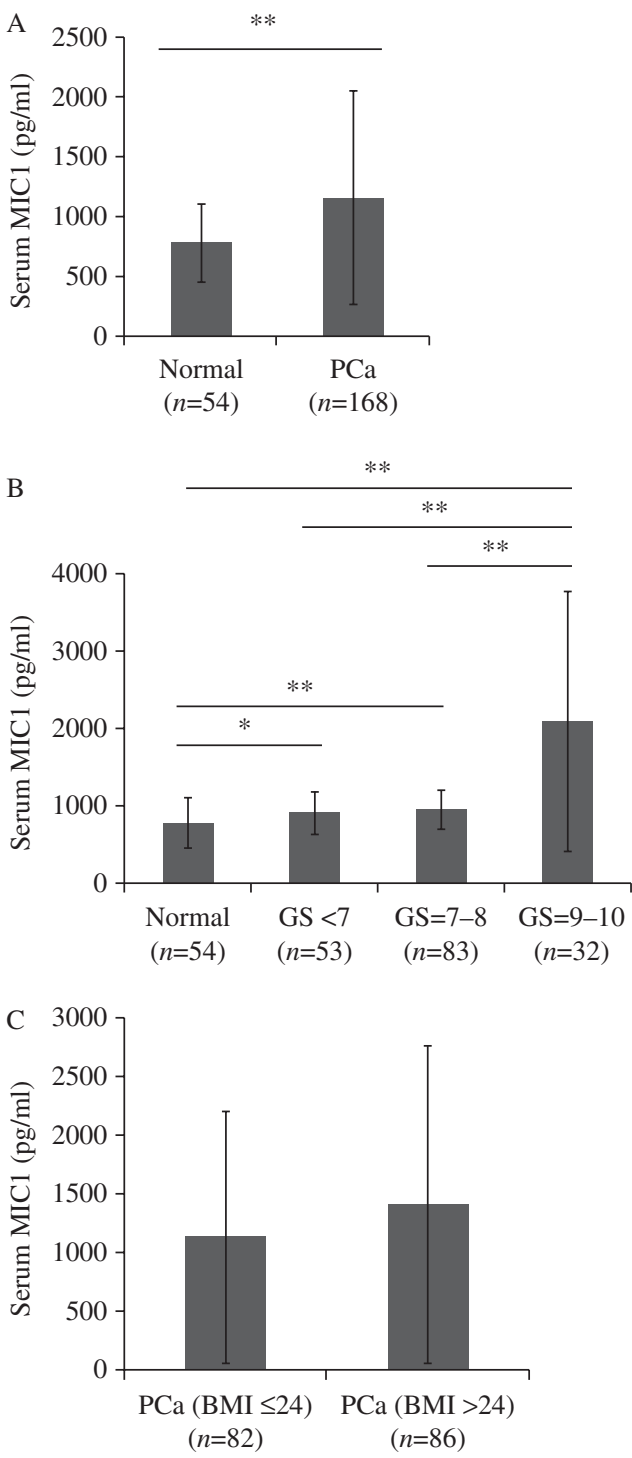

Figure 5

Serum MIC1 levels were significantly higher in patients with localized $\mathrm{PCa}$ than in controls and were associated with a high Gleason score (GS). (A) Serum MIC1 levels from 54 controls and 168 patients with PCa were measured using a human MIC1 ELISA Kit. Mean \pm s.D., $* * P<0.01$. (B) Patients with PCa were categorized into three groups (GS $<7, G S=7-8$, and GS $=9-10$ ) and the serum MIC1 levels in each group were compared with those in the healthy controls. Mean \pm s.D., $* P<0.05, * * P<0.01$. (C) Patients with clinically localized PCa were divided into two groups according to BMI ( $<24$ or $>24$ ) and serum MIC1 levels were compared between the two groups $(1411.3 \pm 1353.3$ and $1137.5 \pm 1076.4 \mathrm{pg} / \mathrm{ml}$ respectively, $P=0.087$ )

(Oberbach et al. 2010, Wen et al. 2011). Increased PA levels regulate DNA-damaged cells and promote the transformation of primary cells, including precancerous cells (Zeng et al. 2008). Although the precise function of PA in PCa cell viability and progression remains unclear, recent evidence has suggested that PA induces MIC1 expression in breast cancer MDA-MB-231 cells (Kim et al. $2008 a$ ). Secreted factors from adipocytes were shown to stimulate MIC1 expression in MDA-MB-231 cells, and PA was shown to be one of the strongest factors inducing MIC1 (Kim et al. 2008a). In this study, we demonstrated that PA stimulated MIC1 expression and secretion in four PCa cell lines, i.e. LNCaP, C42, Du145, and PC3. Furthermore, this study shows that serum MIC1 levels in mice were significantly increased in the HFD group compared with the LFD group, and these levels were significantly correlated with tumor growth in the LNCaP xenograft mouse. These findings indicate that high MIC1 levels induced by PA may be involved in HFD-mediated PCa progression.

The role of MIC1 in PCa remains unclear and controversial. One recent study has demonstrated that cell viability was significantly increased in MIC1 cDNAtransfected LNCaP cells compared with normal LNCaP cells through the activation of the ERK1/2 signal pathway (Chen et al. 2007). In contrast, MIC1 siRNA-expressing LNCaP cells exhibited resistance to protein kinase C-mediated apoptosis, indicating that MIC1 negatively affects LNCaP cell survival (Shim \& Eling 2005). Our in vitro study showed that rMIC1 stimulated the proliferation of LNCaP and C42 cells in a dose-dependent manner. Furthermore, LNCaP and C42 cell viability was significantly increased in the medium containing HFD mouse serum, and this effect was diminished by treatment with MAB957, indicating that extracellular MIC1 may be a growth enhancer in some types of PCa cells. Recent studies have shown that MIC1-overexpressing TRAMP mice exhibited significantly increased metastasis to the liver, kidney, lung, and rectum compared with normal TRAMP mice (Husaini et al. 2012). In addition, intracellular and extracellular MIC1 levels were significantly higher in the metastatic PCa cells (Senapati et al. 2010). In this study, PCa cell-invasive capacity was significantly enhanced in media containing xenograft recipient mouse serum compared with FBS media, and this effect was attenuated in the presence of MAB957. In addition, the invasive capacity of PCa cells was increased by rMIC1 treatment and decreased by treatment with MIC1 siRNA. Furthermore, serum MIC1 levels and MIC1 expression in the xenograft tumors were significantly higher in the HFD group than in the LFD group. MIC1-overexpressing tumor cells efficiently invaded peritumoral venules and lymph vessels in the LNCaP xenograft mouse. ERK is an essential proliferative and metastatic factor that is rapidly activated by MIC1 in breast and gastric cancer cells (Kim et al. 2008b). In our study, ERK activation was significantly

Published by Bioscientifica Ltd. 
increased in the LNCaP cells by treatment with HFD mouse serum, and the effect was diminished by the addition of MAB957. These findings indicate that upregulation of ERK signaling by diet-induced increases in MIC1 may be associated with HFD-induced PCa progression.

Similar to results described in a recent report, the increased serum MIC1 levels observed in the present study were associated with the clinical stage, pathological grade, and PSA levels in PCa (Brown et al. 2009). Serum MIC1 levels were also elevated in obese patients and further increased by the presence of type 2 diabetes mellitus (T2DM; Dostalova et al. 2009). In addition, a recent report has shown that obesity-mediated hyperinsulinemia also induced an increase in serum MIC1 levels (Karczewska-Kupczewska et al. 2012). In this study, PA and an HFD including PA stimulated the production and secretion of MIC1 in PCa cells in vitro and in vivo. These findings indicate that the dietary component or HFD-mediated biological alterations, such as obesity or hyperinsulinemia, may stimulate MIC1 production. In contrast, MIC1 induced anorexia and weight loss in late-stage advanced PCa (Johnen et al. 2007). Moreover, overexpression of MIC1 may lead to decreases in food intake, body weight, and adiposity, both under normal and obesogenic dietary conditions (Macia et al. 2012). Therefore, the balance between increased caloric intake from an HFD and HFD-associated hyper-production of MIC1 may be important for body weight regulation. In this study, serum MIC1 levels significantly increased in Japanese patients with localized early-stage PCa and correlated with the pathological Gleason grade. In addition, serum MIC1 levels tended to be higher in patients with higher BMI (BMI >24) than in those with a lower BMI (BMI <24). Although these findings are intriguing, it remains unknown whether high MIC1 levels are associated with higher grade PCa or whether obesity plays a causative role in PCa progression.

Our previous investigation indicated that an HFD affects many important cytokine signaling pathways, including IGF, TWEAK, and MCP1, and promotes proliferation and invasiveness in PCa (Narita et al. 2008, Huang et al. 2011, 2012). A recent study has demonstrated that an HFD stimulates the production of inflammatory cytokines, including IL6, IL1, and TNF- $\alpha$ (Cortez et al. 2013). In this study, an HFD containing high amounts of PA influenced MIC1 expression and promoted PCa progression. These findings support the view that altered cytokine levels and signaling influenced by FA dietary content may play a significant role in PCa progression (Tete et al. 2012).
In conclusion, we found that PA stimulated MIC1 expression in PCa cells and that an HFD containing PA accelerated PCa tumor growth in vivo and enhanced MIC1 expression. In addition, MIC1 modulated the proliferation and invasive capacity of PCa cells in vitro. In humans, serum MIC1 levels may be associated with cancer aggressiveness and obesity. Therefore, an HFD containing PA may promote growth and invasiveness of PCa cells through the upregulation of MIC1 expression.

\section{Supplementary data}

This is linked to the online version of the paper at http://dx.doi.org/10.1530/ ERC-13-0227.

\section{Declaration of interest}

The authors declare that there is no conflict of interest that could be perceived as prejudicing the impartiality of the research reported.

\section{Funding}

This work was supported by the Japan Society for the Promotion of Science (JSPS; 24592374).

\section{Author contribution statement}

M Huang, S Narita, and T Habuchi designed the experiments; M Huang, S Narita, and $\mathrm{H}$ Nanjo performed the experiments; M Huang, S Narita, T Inoue, N Tsuchiya, S Satoh, H Nanjo, T Sasaki, and T Habuchi analyzed the data; and M Huang, S Narita, and T Habuchi wrote the paper.

\section{References}

Andersson SO, Wolk A, Bergstrom R, Adami HO, Engholm G, Englund A \& Nyren O 1997 Body size and prostate cancer: a 20-year follow-up study among 135006 Swedish construction workers. Journal of the National Cancer Institute 89 385-389. (doi:10.1093/jnci/89.5.385)

Bauskin AR, Brown DA, Junankar S, Rasiah KK, Eggleton S, Hunter M, Liu T, Smith D, Kuffner T, Pankhurst GJ et al. 2005 The propeptide mediates formation of stromal stores of PROMIC-1: role in determining prostate cancer outcome. Cancer Research 65 2330-2336. (doi:10.1158/ 0008-5472.CAN-04-3827)

Blair A \& Fraumeni JF 1978 Geographic patterns of prostate cancer in the United States. Journal of the National Cancer Institute 61 1379-1384.

Bootcov MR, Bauskin AR, Valenzuela SM, Moore AG, Bansal M, He XY, Zhang HP, Donnellan M, Mahler S, Pryor K et al. 1997 MIC-1, a novel macrophage inhibitory cytokine, is a divergent member of the TGF- $\beta$ superfamily. PNAS 94 11514-11519. (doi:10.1073/pnas.94.21.11514)

Brown DA, Ward RL, Buckhaults P, Liu T, Romans KE, Hawkins NJ, Bauskin AR, Kinzler KW, Vogelstein B \& Breit SN 2003 MIC-1 serum level and genotype: associations with progress and prognosis of colorectal carcinoma. Clinical Cancer Research 9 2642-2650.

Brown DA, Stephan C, Ward RL, Law M, Hunter M, Bauskin AR, Amin J, Jung K, Diamandis EP, Hampton GM et al. 2006 Measurement of serum levels of macrophage inhibitory cytokine 1 combined with prostatespecific antigen improves prostate cancer diagnosis. Clinical Cancer Research 12 89-96. (doi:10.1158/1078-0432.CCR-05-1331)

Published by Bioscientifica Ltd. 
Brown DA, Lindmark F, Stattin P, Balter K, Adami HO, Zheng SL, Xu J, Isaacs WB, Gronberg H, Breit SN et al. 2009 Macrophage inhibitory cytokine 1: a new prognostic marker in prostate cancer. Clinical Cancer Research 15 6658-6664. (doi:10.1158/1078-0432.CCR-08-3126)

Chen SJ, Karan D, Johansson SL, Lin FF, Zeckser J, Singh AP, Batra SK \& Lin MF 2007 Prostate-derived factor as a paracrine and autocrine factor for the proliferation of androgen receptor-positive human prostate cancer cells. Prostate 67 557-571. (doi:10.1002/pros.20551)

Cortez M, Carmo LS, Rogero MM, Borelli P \& Fock RA 2013 A high-fat diet increases IL-1, IL- 6 , and TNF- $\alpha$ production by increasing NF- $\kappa \mathrm{B}$ and attenuating PPAR- $\gamma$ expression in bone marrow mesenchymal stem cells. Inflammation 36 379-386. (doi:10.1007/s10753-012-9557-z)

Degeorges A, Hoffschir F, Cussenot O, Gauville C, Le Duc A, Dutrillaux B \& Calvo F 1995 Recurrent cytogenetic alterations of prostate carcinoma and amplification of $c-m y c$ or epidermal growth factor receptor in subclones of immortalized PNT1 human prostate epithelial cell line. International Journal of Cancer 62 724-731. (doi:10.1002/ ijc.2910620613)

Dostalova I, Roubicek T, Bartlova M, Mraz M, Lacinova Z, Haluzikova D, Kavalkova P, Matoulek M, Kasalicky M \& Haluzik M 2009 Increased serum concentrations of macrophage inhibitory cytokine- 1 in patients with obesity and type 2 diabetes mellitus: the influence of very low calorie diet. European Journal of Endocrinology 161 397-404. (doi:10.1530/EJE-09-0417)

Flavin R, Zadra G \& Loda M 2011 Metabolic alterations and targeted therapies in prostate cancer. Journal of Pathology 223 283-294. (doi:10.1002/path.2809)

Giovannucci E, Rimm EB, Colditz GA, Stampfer MJ, Ascherio A, Chute CC $\&$ Willett WC 1993 A prospective study of dietary fat and risk of prostate cancer. Journal of the National Cancer Institute 85 1571-1579. (doi:10.1093/jnci/85.19.1571)

Haversen L, Danielsson KN, Fogelstrand L \& Wiklund O 2009 Induction of proinflammatory cytokines by long-chain saturated fatty acids in human macrophages. Atherosclerosis 202 382-393. (doi:10.1016/ j.atherosclerosis.2008.05.033)

Hromas R, Hufford M, Sutton J, Xu D, Li Y \& Lu L 1997 PLAB, a novel placental bone morphogenetic protein. Biochimica et Biophysica Acta: Gene Structure and Expression 1354 40-44. (doi:10.1016/S01674781(97)00122-X)

Hsing AW \& Devesa SS 2001 Trends and patterns of prostate cancer: what do they suggest? Epidemiologic Reviews 23 3-13. (doi:10.1093/ oxfordjournals.epirev.a000792)

Huang M, Narita S, Tsuchiya N, Ma Z, Numakura K, Obara T, Tsuruta H, Saito M, Inoue T, Horikawa Y et al. 2011 Overexpression of Fn14 promotes androgen-independent prostate cancer progression through MMP-9 and correlates with poor treatment outcome. Carcinogenesis 32 1589-1596. (doi:10.1093/carcin/bgr182)

Huang M, Narita S, Numakura K, Tsuruta H, Saito M, Inoue T, Horikawa Y, Tsuchiya N \& Habuchi T 2012 A high-fat diet enhances proliferation of prostate cancer cells and activates MCP-1/CCR2 signaling. Prostate 72 1779-1788. (doi:10.1002/pros.22531)

Husaini Y, Qiu MR, Lockwood GP, Luo XW, Shang P, Kuffner T, Tsai VW, Jiang L, Russell PJ, Brown DA et al. 2012 Macrophage inhibitory cytokine-1 (MIC-1/GDF15) slows cancer development but increases metastases in TRAMP prostate cancer prone mice. PLOS ONE 7 e43833. (doi:10.1371/journal.pone.0043833)

Johnen H, Lin S, Kuffner T, Brown DA, Tsai VW, Bauskin AR, Wu L, Pankhurst G, Jiang L, Junankar S et al. 2007 Tumor-induced anorexia and weight loss are mediated by the TGF- $\beta$ superfamily cytokine MIC- 1 . Nature Medicine 13 1333-1340. (doi:10.1038/nm1677)

Karczewska-Kupczewska M, Kowalska I, Nikolajuk A, Adamska A, Otziomek E, Gorska M \& Straczkowski M 2012 Hyperinsulinemia acutely increases serum macrophage inhibitory cytokine-1 concentration in anorexia nervosa and obesity. Clinical Endocrinology 76 46-50. (doi:10.1111/j.1365-2265.2011.04139.x)
Kim JH, Kim KY, Jeon JH, Lee SH, Hwang JE, Lee JH, Kim KK, Lim JS, Kim KI, Moon EY et al. 2008a Adipocyte culture medium stimulates production of macrophage inhibitory cytokine 1 in MDA-MB-231 cells. Cancer Letters 261 253-262. (doi:10.1016/j.canlet.2007.11.020)

Kim KK, Lee JJ, Yang Y, You KH \& Lee JH 2008b Macrophage inhibitory cytokine-1 activates AKT and ERK-1/2 via the transactivation of ErbB2 in human breast and gastric cancer cells. Carcinogenesis 29 704-712. (doi:10.1093/carcin/bgn031)

Koopmann J, Buckhaults P, Brown DA, Zahurak ML, Sato N, Fukushima N, Sokoll LJ, Chan DW, Yeo CJ, Hruban RH et al. 2004 Serum macrophage inhibitory cytokine 1 as a marker of pancreatic and other periampullary cancers. Clinical Cancer Research 10 2386-2392. (doi:10.1158/ 1078-0432.CCR-03-0165)

Kurahashi N, Inoue M, Iwasaki M, Sasazuki S \& Tsugane AS 2008 Dairy product, saturated fatty acid, and calcium intake and prostate cancer in a prospective cohort of Japanese men. Cancer Epidemiology, Biomarkers \& Prevention 17 930-937. (doi:10.1158/1055-9965. EPI-07-2681)

Macia L, Tsai VW, Nguyen AD, Johnen H, Kuffner T, Shi YC, Lin S, Herzog H, Brown DA, Breit SN et al. 2012 Macrophage inhibitory cytokine 1 (MIC-1/GDF15) decreases food intake, body weight and improves glucose tolerance in mice on normal \& obesogenic diets. PLOS ONE 7 e34868. (doi:10.1371/journal.pone.0034868)

Namiki M, Akaza H, Lee SE, Song JM, Umbas R, Zhou L, Lee BC, Cheng C, Chung MK, Fukagai T et al. 2010 Prostate Cancer Working Group report. Japanese Journal of Clinical Oncology 40 (Suppl 1) i70-i75. (doi:10.1093/jico/hyq130)

Narita S, Tsuchiya N, Saito M, Inoue T, Kumazawa T, Yuasa T, Nakamura A $\&$ Habuchi T 2008 Candidate genes involved in enhanced growth of human prostate cancer under high fat feeding identified by microarray analysis. Prostate 68 321-335. (doi:10.1002/pros.20681)

Oberbach A, Schlichting N, Bluher M, Kovacs P, Till H, Stolzenburg JU \& Neuhaus J 2010 Palmitate induced IL-6 and MCP-1 expression in human bladder smooth muscle cells provides a link between diabetes and urinary tract infections. PLOS ONE 5 e10882. (doi:10.1371/ journal.pone.0010882)

Paralkar VM, Vail AL, Grasser WA, Brown TA, Xu H, Vukicevic S, Ke HZ, Qi H, Owen TA \& Thompson DD 1998 Cloning and characterization of a novel member of the transforming growth factor- $\beta /$ bone morphogenetic protein family. Journal of Biological Chemistry $\mathbf{2 7 3}$ 13760-13767. (doi:10.1074/jbc.273.22.13760)

Senapati S, Rachagani S, Chaudhary K, Johansson SL, Singh RK \& Batra SK 2010 Overexpression of macrophage inhibitory cytokine-1 induces metastasis of human prostate cancer cells through the FAK-RhoA signaling pathway. Oncogene 29 1293-1302. (doi:10.1038/ onc.2009.420)

Shim M \& Eling TE 2005 Protein kinase C-dependent regulation of NAG-1/placental bone morphogenic protein/MIC-1 expression in LNCaP prostate carcinoma cells. Journal of Biological Chemistry $\mathbf{2 8 0}$ 18636-18642. (doi:10.1074/jbc.M414613200)

Shimizu H, Ross RK, Bernstein L, Yatani R, Henderson BE \& Mack TM 1991 Cancers of the prostate and breast among Japanese and white immigrants in Los Angeles County. British Journal of Cancer 63 963-966. (doi:10.1038/bjc.1991.210)

Strom SS, Yamamura Y, Forman MR, Pettaway CA, Barrera SL \& DiGiovanni J 2008 Saturated fat intake predicts biochemical failure after prostatectomy. International Journal of Cancer 122 2581-2585. (doi:10.1002/ ijc.23414)

Tete S, Nicoletti M, Saggini A, Maccauro G, Rosati M, Conti F, Cianchetti E, Tripodi D, Toniato E, Fulcheri M et al. 2012 Nutrition and cancer prevention. International Journal of Immunopathology and Pharmacology 25 573-581.

Tominaga S 1985 Cancer incidence in Japanese in Japan, Hawaii, and western United States. National Cancer Institute Monographs 69 83-92. 
Wen H, Gris D, Lei Y, Jha S, Zhang L, Huang MT, Brickey WJ \& Ting JP 2011 Fatty acid-induced NLRP3-ASC inflammasome activation interferes with insulin signaling. Nature Immunology 12 408-415. (doi:10.1038/ni.2022)

Wollmann W, Goodman ML, Bhat-Nakshatri P, Kishimoto H, Goulet RJ Jr, Mehrotra S, Morimiya A, Badve S \& Nakshatri H 2005 The macrophage inhibitory cytokine integrates AKT/PKB and MAP kinase signaling pathways in breast cancer cells. Carcinogenesis 26 900-907.

(doi:10.1093/carcin/bgi031)
Wu HC, Hsieh JT, Gleave ME, Brown NM, Pathak S \& Chung LW 1994 Derivation of androgen-independent human LNCaP prostatic cancer cell sublines: role of bone stromal cells. International Journal of Cancer $\mathbf{5 7}$ 406-412. (doi:10.1002/ijc.2910570319)

Zeng L, Wu GZ, Goh KJ, Lee YM, Ng CC, You AB, Wang J, Jia D, Hao A, Yu Q et al. 2008 Saturated fatty acids modulate cell response to DNA damage: implication for their role in tumorigenesis. PLOS ONE 3 e2329. (doi:10.1371/journal.pone.0002329)

Received in final form 2 November 2013

Accepted 6 November 2013
Published by Bioscientifica Ltd. 